\title{
Optimal Placement and Sizing of Capacitor and Power-Electronic Interfaced Distributed Generation in Heavy Harmonic Polluted Systems
}

\author{
Mohamadreza Heydari Sharafdark olai \\ Staff member of Mazandaran regional electric company, Iran \\ Email: Hatebird85@gmail.com \\ Hamed Dehghan Niyazi \\ Azad university of yazd, Iran \\ Email: dehghann@yahoo.com \\ Tahe re daemi \\ Faculty member of azad university of yazd, Iran \\ Email: T_daemi@yahoo.com \\ Ali Akbar Kasiri \\ Email: Nimak79@yahoo.com
}

\begin{abstract}
Presence of distributed generation (DG) in distribution systems has significant impacts on the operational characteristics of these systems, also using capacitor for reactive compensation and loss reduction is so common. Injected harmonic currents from non-linear loads into distribution system distort all of voltages and currents and must be considered when placing the capacitor banks so that the resonance will not occur. Distributed Generation is often connected to the network via power-electronic interfaces for a proper coupling with the distribution networks. Inverters are capable of producing harmonic components and can be used as ancillary services for reducing harmonics by designing of a proper controlling system. In this paper discrete particle swarm optimization (DPSO) approach is used for the optimal placement and sizing of distributed generations and capacitors in distorted distribution systems for simultaneous voltage profile improvement, loss and total harmonic distortion (THD) reduction. Constraints include voltage limit, voltage THD, number/ size of capacitors and generators. For evaluating the proposed algorithm, the IEEE 33-bus test system is modified and employed.
\end{abstract}

Index Terms - Capacitor, Distributed Generation, Discrete Particle Swarm Optimization, Harmonic, Optimal Placemen, Power-Electronic, Resonance.

\section{INTRODUCTION}

Studies have indicated that approximately $13 \%$ of generated power is consumed as loss at the distribution level. In addition, with the application of loads, the voltage profile tends to drop along distribution feeders below acceptable operating limits. Along with power losses and voltage drops, the increasing growth in electricity demand requires upgrading the infrastructure of distribution systems. In this situation DISTRIBUTED GENERATION (DG) may play an important role in the electric power systems. Distributed Generation is a small electric power source connected to the distribution network near consumption. SHUNT capacitors are installed in distribution systems in order to reduce power losses, regulate bus voltage and improve power factor by generating reactive power. A ll of these advantages will be achieved only on the condition, these (DG\& Capacitor) placed in proper buses. Any improper placing may adverse system's condition. One assumption that is still being made in formulating the capacitor placement problem is that all loads are considered linear. In practice, a portion of the electric load is nonlinear due to the widespread use of electronics-based devices. Nonlinear loads must be taken into account for placing of capacitors because they show low impedance at harmonic frequencies which is so ideal for flowing harmonic currents throw them and they may amplify harmonic amplitude at resonance frequencies and damage the system's components. Distributed Generation is often connected to the network via power-electronic interfaces (converter or inverter) for a proper coupling with the distribution networks. These converters (inverters) are well-designed and controlled to generate an almost pure sinusoidal output voltage. On the other hand, Inverters are capable of producing harmonic components and can be used as ancillary services for reducing harmonics by designing of a proper controlling system. This controlling system controls the inverter's switches in such a way a particular harmonic component is produced in the output of the inverter which opposes its counterpart on the load side. This will lead to cancellation of harmonics. There have been some studies for optimal placing such as: tabu 
search [1], analytical approaches [2].[3], second-order algorithm [4], meta-heuristic approaches[5].[6], fuzzyGA algorithm[7], etc. Most of these techniques suffer from the inability to escape local optimal and burden heavy computational time. PSO (particle swarm optimization) is a good method which is fast and has ability to escape local optimal. PSO is a self-adaptive search optimization was introduced by Kennedy and Ebhart[8]. PSO has been applied to many optimization problems such as: dynamic systems [9], optimal capacitor placement in distribution system [10], constrained optimization [11], mu lti- objective optimization proble ms [12], etc. So me works have used PSO for optimal placing of capacitors, it was considered as a continuous problem but as we know capacitors are commercially available in discrete sizes, so in this paper a modified version of PSO which is suitable for discrete problems and is called discrete particle swarm optimization (DPSO) or binary particle swarm optimization is used.

The rest of this paper is organized as follows: in section II an ancillary service for improving system's power quality will be introduced. Problem formulation for the objective function for improving voltage profile and minimization of loss and THD is presented in section III. In section IV the PSO algorithm is described briefly. The results of DG and capacitor placement on 33-bus test system are presented and discussed in section V. Finally, section VI summarizes the main points and results of this paper.

\section{ANCILLARY SERVICE}

The Today's distributed generators and appliances are increasingly built up with power electronics. This trend is expected to grow further in the future. Fig. 1 shows the interface of an inverter-based DG unit operating in standalone mode. $V_{S}$ Represents the rms value of the ac voltage generated by the inverter. The DG source is tied to the point of common coupling (PCC) through an inverter and a series inductor having an inductance" L" and an internal resistance "R". The presence of nonlinear loads affects the performance of all the loads connected at the PCC. In this case, the nonlinear current $\left(I_{N L}\right)$, drawn by the nonlinear load, leads to a nonlinear voltage drop $\left(V_{\text {line }}\right)$ across the line impedance.

$$
V_{\text {line }}=V_{1}+\Sigma V_{\mathrm{hn}}
$$

Where $V_{1}$ is the fundamental component of $V_{\text {line }}$ and $V_{h n}$ represents its nth harmonic component. Hence, even if the inverter is controlled to generate a sinusoidal output voltage, the voltage at the PCC, $\left(V_{\mathrm{PCC}}=\mathrm{V}_{\mathrm{S}}-\mathrm{V}_{\text {line }}\right)$ will be nonsinusoidal. The problem of distorted supply voltage at the PCC, as shown in Fig. 1, can be handled by compensating the nonlinear drop across the line impedance. The compensation voltages, required to eliminate voltage harmonics, are injected across the compensating transformer's secondary windings which are in series with the line. Fig. 2 shows the series compensation scheme, where voltage $\Sigma V_{\mathrm{hn}}$, equal to the nonlinear drop across the line impedance, is applied externally in series with the source to produce sinusoidal voltage at the PCC.

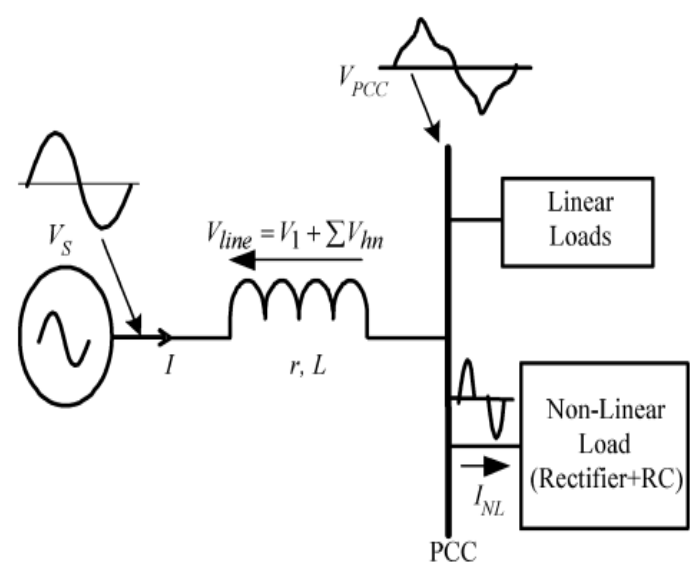

Fig. 1. DG source interface with the loads at the PCC

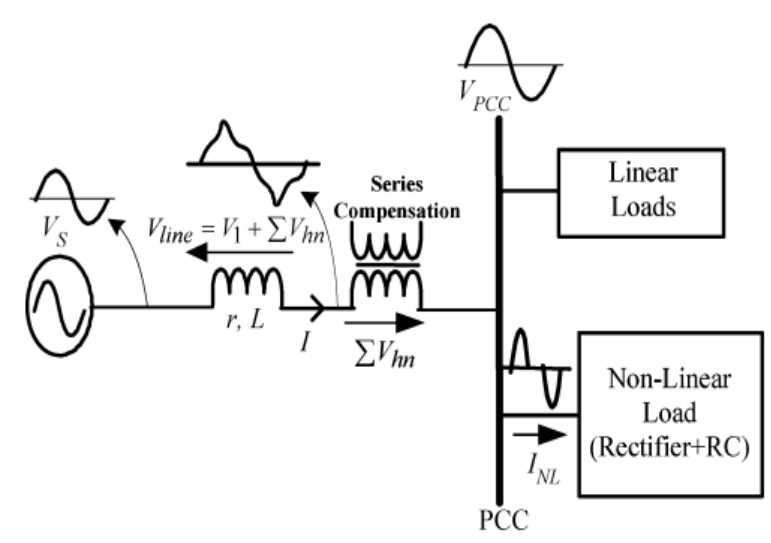

Fig. 2. Series compensation to compensate the voltage drop across line impedance

As mentioned, converters are capable of producing harmonics and can be used as ancillary services for compensating of harmonic voltage drop across the line impedance instead of using external compensator just by using of a good controlling system. Some good control systems are designed and introduced in papers. In this paper, the control system of [13] is used. Fig 3 shows this control system. The detail of this system is fully described in [13]. Harmonic calculator and harmonic generator are two main parts of this control system. Harmonic calculator, calculates the phase and amplitude of harmonics in the system and harmonic generator, generates harmonics which are same in the amplitude and 180 degree shifted phase with their counterpart on the load side. This result cancellation of nonlinear drop across the line impedance to achieve a sinusoidal voltage at the PCC. This controlling system is called harmonic injection system. 


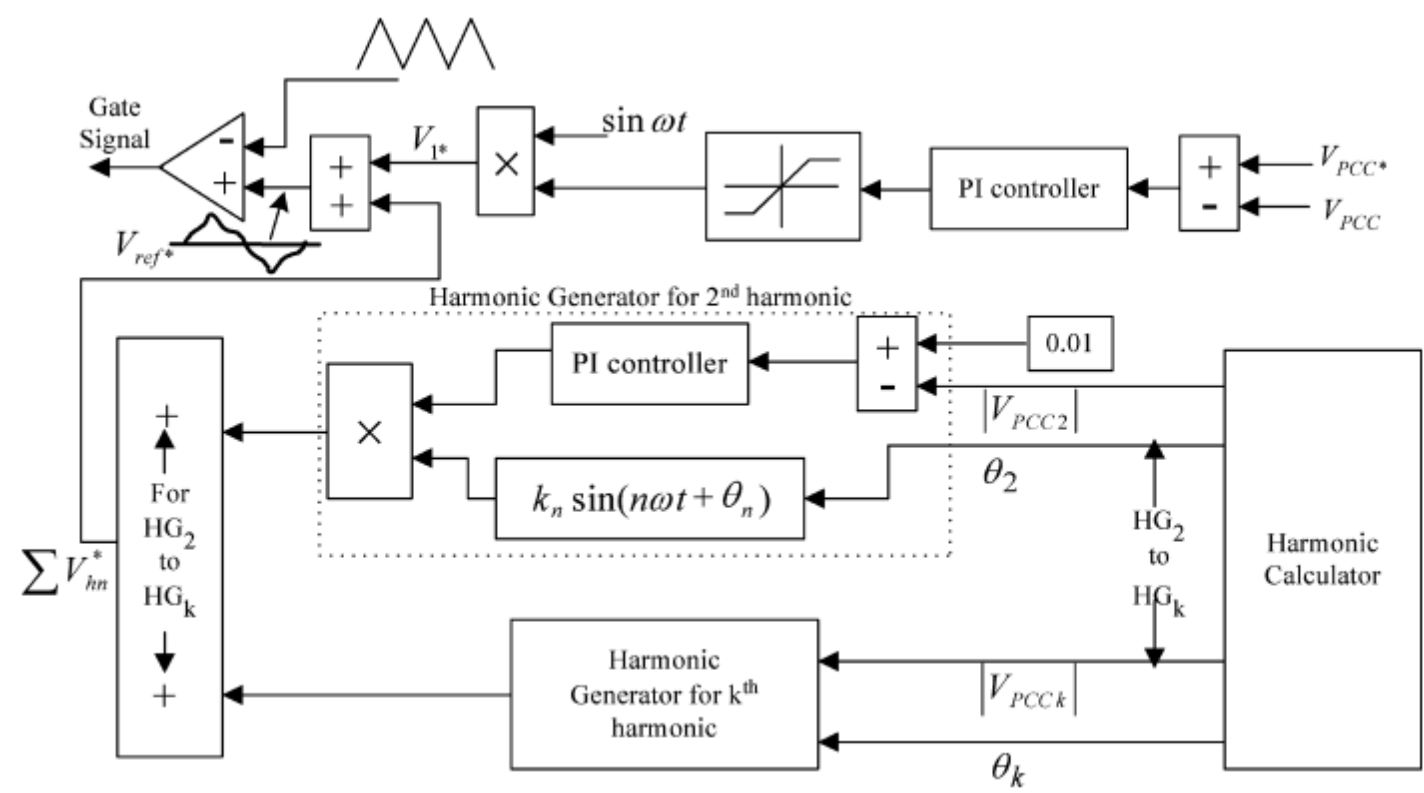

Fig. 3. Schematic diagram of the control scheme

\section{PROBLEM FORMULATION}

In this paper the following as sumptions are made:

- Capacitors are fixed type.

- Both linear and non-linear loads are presented in a 3wired 3-phase system.

\subsection{Constraints}

Voltage constraint will be defined as follows:

$$
V^{\min } \leq \sqrt{\Sigma_{h}\left(V_{i}^{h}\right)^{2}} \leq V^{\max }
$$

Where $\mathrm{V}^{\mathrm{min}}$ is lower, $\mathrm{V}^{\max }$ is upper bounds of rms voltage and $V_{i}^{h}$ is $h^{\text {th }}$ harmonic order of voltage at bus $i$. In this paper $\mathrm{V}^{\min }=0.95$ and $\mathrm{V}^{\max }=1.05$.

Total harmonic distortion of voltage (THD) should be less than the maximum of allowable $\left(T H D_{v}^{\max }\right)$.

$$
T H D_{v, i}=\left(\begin{array}{c}
{\left[\sqrt{\Sigma_{h \neq 1}^{\left(v_{i}^{h}\right)^{2}}}\right] / V_{i}^{1}} \\
\leq T H D_{v}^{\max }
\end{array}\right.
$$

Where $T H D_{v, i}$ is the total harmonic distortion of voltage of bus $\mathrm{i}$

In this paper according to IEEE-519, $\mathrm{THD}_{\mathrm{v}}^{\max }=0.05$.

\subsection{Indexing}

For forming of objective function some indexes are defined.

\subsubsection{Voltage Deviation Index}

This index is for improving of voltage profile and defined as follows:

$$
V_{\text {index }}=\sum_{i=1}^{n}\left(\frac{V_{\text {nom }}-V_{i}}{V_{\text {nom }}}\right)^{2}
$$

Where $V_{\text {nom }}$ is the nominal of system voltage $\left(V_{\text {nom }}=1\right), V_{i}$ is the voltage at node $i$ and $n$ is number of buses.

\section{2 .2 Active and Reactive Power Loss Index}

This index is for improving of voltage profile and defined as follows:

$$
\begin{aligned}
P L_{\text {index }} & =\frac{P_{L}}{P_{L-N O}} \\
Q L_{\text {index }} & =\frac{Q_{L}}{Q_{L-N O}}
\end{aligned}
$$

Where $P_{\mathrm{L}}, \mathrm{Q}_{\mathrm{L}}$ are active and reactive power losses after installation of DG and capacitor respectively and $\mathrm{P}_{\mathrm{L}-\mathrm{NO}}, \mathrm{Q}_{\mathrm{L}-\mathrm{NO}}$ are active and reactive power loss before installation.

\section{2 .3 THD Index}

This index is for minimizing of total harmonic distortion:

$$
T H D_{\text {index }}=\sum_{i=1}^{n}\left(T H D_{i} / T H D_{i N O}\right)
$$

Where $\mathrm{THD}_{\mathrm{i}}$ is the total harmonic distortion of bus I after installation and $T H D_{i N O}$ is the total harmonic distortion of bus I before installation.

\subsubsection{Resonance Index (RES-I)}

Many works concerning capacitor placement, consider all loads are linear, recently some works take non-linear loads into account, so the capacitor placement problem 
mixed with harmonic consideration, but as it is shown in [18] even in these works, capacitor placement led to harmonic resonance at one or some harmonic frequencies. In this paper there is a term in the objective function which prevents harmonic resonance. So resonance index is defined as follow:

$$
\begin{aligned}
R E S_{\text {index }}=\sum_{\mathrm{i}=1}^{\mathrm{n}} \sum_{\mathrm{h}=1}^{\mathrm{m}}\left(\mathrm{V}_{\mathrm{i}}^{\mathrm{h}} / \mathrm{V}_{\mathrm{i}}^{\mathrm{h}-\mathrm{no}}\right) \\
+\sum_{\mathrm{i}=1}^{\mathrm{n}} \sum_{\mathrm{h}=1}^{\mathrm{m}}\left(\mathrm{I}_{\mathrm{i}}^{\mathrm{h}} / \mathrm{I}_{\mathrm{i}}^{\mathrm{h}-\mathrm{no}}\right)
\end{aligned}
$$

Where $V_{i}^{h}, I_{i}^{h}$ are the voltage and current of bus $I$ at $\mathrm{h}^{\text {th }}$ harmonic order after installation and $\mathrm{V}_{\mathrm{i}}^{\mathrm{h}-\mathrm{no}}, \mathrm{I}_{\mathrm{i}}^{\mathrm{h}-\mathrm{no}}$ are before installation of DG and capacitor.

\subsection{Objective Function}

By introducing above indexes objective function is defined as follows:

$$
\begin{aligned}
F=\alpha_{1} V_{\text {index }}+ & \alpha_{2} P L_{\text {index }}+\alpha_{3} Q L_{\text {index }} \\
& +\alpha_{4} T H D_{\text {index }}+\alpha_{5} R E S_{\text {index }} \\
& +P F
\end{aligned}
$$

Where $\alpha$ is the index weight, these weights indicate the importance of each index in the placement problem. They depend on the required analysis.

$$
\sum_{\alpha=1}^{5} \alpha=1 \quad, \quad \alpha \in\left[\begin{array}{ll}
0 & 1
\end{array}\right]
$$

In table 1 these weights are defined, for selecting these weights, the guides of [14].[15] are used.

Table 1. index weights

\begin{tabular}{|c|c|c|}
\hline index & Index weight & value \\
\hline$V_{\text {index }}$ & $\alpha_{1}$ & 0.3 \\
\hline$P L_{\text {index }}$ & $\alpha_{2}$ & 0.2 \\
\hline$Q L_{\text {index }}$ & $\alpha_{3}$ & 0.2 \\
\hline$T H D_{\text {index }}$ & $\alpha_{4}$ & 0.15 \\
\hline$R E S_{\text {index }}$ & $\alpha_{5}$ & 0.15 \\
\hline
\end{tabular}

PF is the penalty factor which has two values zero and a very big number. If any particle violates any above constraints, the PF will be set to the big number and make the objective function become so big. This result omitting of that particle from the solution.

\section{PSO ALGORITHM}

The particle swarm optimization algorithm is a stochastic optimization algorithm which maintains a swarm of candidate solutions, referred to as particles, they are members in the population, have their own positions and velocities, and they fly around the problem space in the swarms searching for the position of optima.
PSO is initialized with a group of random particles and then searches for optima by updating generations. In every iteration, each particle is updated by following two "best" values. The first one is the best solution it has achieved so far. This value is called $P_{\text {best }}$. Another "best" value tracked by the particle swarm optimizer is the best value, obtained so far by any particle in the population. This best value is a global best and called $g_{\text {best }}$. After finding the two best values, the particle updates its velocity and positions with following formulas.

$$
\begin{aligned}
x_{i}{ }^{(\mathrm{t}+1)}=\mathrm{x}_{\mathrm{i}}{ }^{(\mathrm{t})}+ & \mathrm{v}_{\mathrm{i}}{ }^{(\mathrm{t}+1)} \\
v_{i}^{(t+1)}=w \cdot v_{i}^{(t)} & +c_{1} \text { rand } \\
& \times\left(p_{\text {best }_{i}}-x_{i}\right) \\
& +c_{2} \text { rand } \\
& \times\left(\text { g }_{\text {best }_{i}}-x_{i}\right)
\end{aligned}
$$

Where $\mathrm{x}$ and $\mathrm{v}$ are the particle position and velocity of the particle respectively. $\mathrm{w}$ is the inertia weight, $\mathrm{c}_{1}$ and $\mathrm{c}_{2}$ are the acceleration constants, and $r_{1}, r_{2}$ are two rando $m$ values in range $[0,1]$. The acceleration constants $\left(c_{1}, c_{2}\right)$ control how far a particle will move in a single iteration. Typically these both are set to a value of 2 . The inertia weight (w) is used to control the convergence of behavior of PSO. Small values of (w ) lead to more rapid convergence usually on suboptimal position, but large value may prevent divergence. In general the inertia weight is set according to the following equation:

$$
w=w_{\max }-\left(\frac{\left(w_{\max }-w_{\min }\right)}{i t e r_{\max }}\right) . i t e r
$$

For binary discrete search space, Kennedy and Ebhart [21] have adopted the PSO to search in binary space by applying a sigmoid transformation to the velocity component given in (14) to squash the velocities into a range $[0,1]$, and force the component values of position to be 0 or 1 . The equation for updating positions in (11) then is replaced by (15)

$$
\begin{aligned}
& \operatorname{sigmoid}\left(v_{i}^{k}\right)=\frac{1}{1+e^{-v_{i}^{k}}} \\
& x_{i}^{k}= \begin{cases}1 & \text { if rand }<\operatorname{sigmoid}\left(v_{i}^{k}\right) \\
0 & \text { other } \text { whise }\end{cases}
\end{aligned}
$$

\section{Simulation RESUlt S:}

The presented algorithm was implemented in Matlab computing environment. In order to evaluate the proposed algorith $\mathrm{m}$, the $12.6 \mathrm{kv} 33$-bus IEEE distribution systemis modified and applied.

The single diagram of this system is shown in Fig.4. The specification of this system is given in [17] two none-linear loads are replaced with loads in buses 5 and 26. These loads are two six-pulse converters with active and reactive power of $1 \mathrm{MW}$ and $0.75 \mathrm{MVAR}$. The harmonic current spectra of these converters are given in table 2 . 


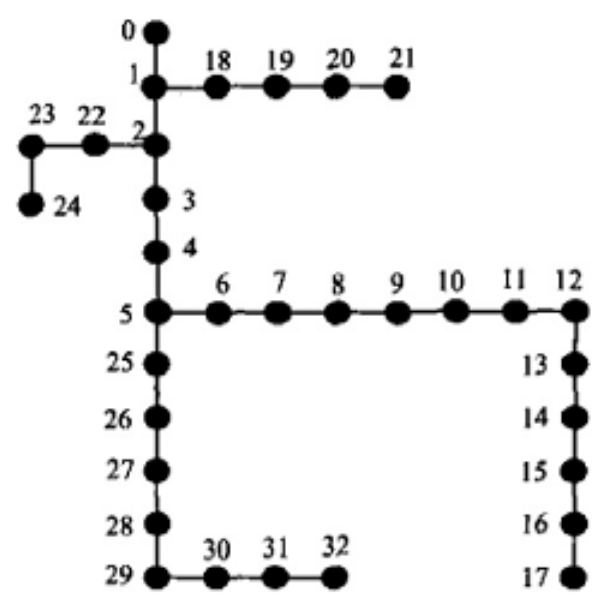

Fig. 4. single line diagram of 33-bus IEEE distribution system

Table 2. six-pulse converter harmonic spectra

\begin{tabular}{|c|c|}
\hline Harmonic order & Percentage of harmonic current \\
\hline 1 & 100 \\
\hline 5 & 20 \\
\hline 7 & 14 \\
\hline 11 & 9 \\
\hline 13 & 8 \\
\hline 17 & 6 \\
\hline 19 & 5 \\
\hline 23 & 4 \\
\hline 25 & 4 \\
\hline
\end{tabular}

Capacitors and Distributed generations are commercially available in discrete sizes. In table 3and 4 the size of capacitor bank and DG are given:

Table 3. capacitor sizes

\begin{tabular}{|c|c|c|}
\hline $\begin{array}{c}\text { Capacitor } \\
(\text { KVAR)ar) }\end{array}$ & $\begin{array}{c}\text { Capacitor } \\
(\text { KVAR) }) \text { ar })\end{array}$ & $\begin{array}{c}\text { Capacitor } \\
(\text { KVAR) }) a r)\end{array}$ \\
\hline 150 & 1500 & 2850 \\
\hline 300 & 1650 & 3000 \\
\hline 450 & 1800 & 3150 \\
\hline 600 & 1950 & 3300 \\
\hline 750 & 2100 & 3450 \\
\hline 900 & 2250 & 3600 \\
\hline 1050 & 2400 & 3750 \\
\hline 1200 & 2550 & 3900 \\
\hline 1350 & 2700 & 4050 \\
\hline
\end{tabular}

Table 4. DG sizes

\begin{tabular}{|c|c|c|c|c|c|}
\hline $\begin{array}{c}\text { DG SIZES } \\
(\mathrm{KW})\end{array}$ & 100 & 300 & 800 & 3000 & 5000 \\
\hline
\end{tabular}

This simulation contains two scenarios.

\subsection{Scenario1:}

In most papers only converters are considered as harmonic sources and the effect of nonlinear loads are not taken into account. In this scenario we come closer to reality and take the non-linear loads into account. In this scenario $20 \%$ of loads on bus es are considered non-linear. In this scnario Distributed generations are not armed with harmonic injection system.

It is obvious system is heavy harmonic polluted. In table 5, rms voltages and THD of all buses for the base case are demonstrated. As observed in table 5, THD of some buses are reached to $13 \%$.

Table 5. bus voltage and THD before installation

\begin{tabular}{|c|c|c|c|c|c|}
\hline Bus number & $\mathrm{V}_{\text {rms }}$ & THD $_{\mathrm{v}}$ & Bus number & $\mathrm{V}_{\text {rms }}$ & THD $_{\mathrm{v}}$ \\
\hline 0 & 1 & - & 17 & 0.8737 & 12.79 \\
\hline 1 & 0.9952 & 0.35 & 18 & 0.9947 & 0.37 \\
\hline 2 & 0.9718 & 2.27 & 19 & 0.9911 & 0.52 \\
\hline 3 & 0.9577 & 3.67 & 20 & 0.9904 & 0.55 \\
\hline 4 & 0.9436 & 5.15 & 21 & 0.9898 & 0.58 \\
\hline 5 & 0.9103 & 10.68 & 22 & 0.9682 & 2.40 \\
\hline 6 & 0.9069 & 11.03 & 23 & 0.9615 & 2.66 \\
\hline 7 & 0.9020 & 11.20 & 24 & 0.9582 & 2.79 \\
\hline 8 & 0.8957 & 11.53 & 25 & 0.9068 & 11.13 \\
\hline 9 & 0.8898 & 11.83 & 26 & 0.9021 & 11.75 \\
\hline 10 & 0.8889 & 11.86 & 27 & 0.8906 & 12.42 \\
\hline 11 & 0.8874 & 11.92 & 28 & 0.8824 & 12.91 \\
\hline 12 & 0.8813 & 12.26 & 29 & 0.8788 & 13.08 \\
\hline 13 & 0.8791 & 12.43 & 30 & 0.8747 & 13.35 \\
\hline 14 & 0.8777 & 12.52 & 31 & 0.8738 & 13.42 \\
\hline 15 & 0.8763 & 12.60 & 32 & 0.8735 & 13.44 \\
\hline 16 & 0.8743 & 12.75 & & & \\
\hline & & & & & \\
\hline
\end{tabular}

The DPSO algorithm is applied in this system for placement of capacitor and distributed generation for improving voltage profile and reducing loss and THD. In table 6 the locations and sizes of capacitors and Distributed generations after running of the algorithm are given. In table 7, rms voltages and THD of all buses after installation of capacitor and DG are demonstrated.

In this scenario distributed generations don't use any harmonic controlling system, but as it is observed in table 7 , installation of these stuffs result decreasing of THD. The reason is, installation of capacitors and distributed generations don't have any effect on the amplitude of individual harmonics, just increase the amplitude of fundamental harmon ic and result decreasing of THD. In a light harmonic polluted system this method is so useful for improving power quality.

As observed in table 6, the algorithm set two large DGs on the buses 5 and 26 which two six pulse converters as powerful harmonic sources are on these busses. THD of the system is decreased by increasing the fundamental harmonic of buses. As observed in table 7, still THD of some buses are more than the acceptable range of defined by IEEE-519 standard. Increasing of fundamental 
harmonic can't be continued to any level because one of the main constraints is voltage level, so for reducing THD, any more, by this method (increasing the amplitude of fundamental harmonic) voltage level will exceed the upper boundary (1.05). The algorithm doesn't let this happen because the weight index of voltage is greater than the weight index of THD. In table 8 and Fig.5 and 6 the results of two cases (before installation and after installation) are compared.

Table 6. the locations of capacitors and DGs with proposed method

\begin{tabular}{|c|c|c|c|c|c|}
\hline Bus & $\begin{array}{c}\text { Capacitor } \\
(\text { KVAR })\end{array}$ & $\begin{array}{c}\text { DG } \\
(\mathrm{KW})\end{array}$ & Bus & $\begin{array}{c}\text { Capacitor } \\
\text { (KVAR) }\end{array}$ & $\begin{array}{c}\text { DG } \\
(\mathrm{KW})\end{array}$ \\
\hline 0 & - & - & 17 & - & - \\
\hline 1 & - & - & 18 & - & - \\
\hline 2 & 1200 & - & 19 & - & - \\
\hline 3 & - & - & 20 & - & - \\
\hline 4 & - & - & 21 & - & - \\
\hline 5 & - & 3000 & 22 & - & - \\
\hline 6 & - & - & 23 & - & - \\
\hline 7 & - & - & 24 & - & - \\
\hline 8 & 2400 & - & 25 & - & - \\
\hline 9 & - & - & 26 & - & 3000 \\
\hline 10 & - & - & 27 & - & - \\
\hline 11 & - & - & 28 & 2700 & - \\
\hline 12 & - & - & 29 & - & - \\
\hline 13 & 2700 & - & 30 & - & - \\
\hline 14 & - & - & 31 & - & - \\
\hline 15 & 3300 & - & 32 & 3600 & - \\
\hline 16 & - & - & & & \\
\hline
\end{tabular}

Table 7. bus voltage and THD after installation of capacitor and DG

\begin{tabular}{|c|c|c|c|c|c|}
\hline $\begin{array}{c}\text { Bus } \\
\text { number }\end{array}$ & $\mathrm{V}_{\text {rms }}$ & $\mathrm{THD}_{\mathrm{v}}$ & $\begin{array}{c}\text { Bus } \\
\text { number }\end{array}$ & $\mathrm{V}_{\text {rms }}$ & $\begin{array}{c}\mathrm{THD}_{\mathrm{v}} \\
\mathrm{THD}_{\mathrm{v}}\end{array}$ \\
\hline 0 & 1 & - & 17 & 1.0132 & 5.4777 \\
\hline 1 & 1.0005 & 0.18973 & 18 & 0.99997 & 0.21106 \\
\hline 2 & 1.0045 & 1.1678 & 19 & 0.99641 & 0.35196 \\
\hline 3 & 1.0103 & 1.8094 & 20 & 0.99571 & 0.3852 \\
\hline 4 & 1.014 & 2.5589 & 21 & 0.99507 & 0.41778 \\
\hline 5 & 1.0211 & 5.2551 & 22 & 1.001 & 1.2834 \\
\hline 6 & 1.0302 & 4.6682 & 23 & 0.99445 & 1.5237 \\
\hline 7 & 1.0387 & 4.5138 & 24 & 0.99119 & 1.6443 \\
\hline 8 & 1.033 & 4.7119 & 25 & 1.0213 & 5.4831 \\
\hline 9 & 1.0278 & 4.8969 & 26 & 1.0218 & 5.7991 \\
\hline 10 & 1.027 & 4.9144 & 27 & 1.0306 & 5.5281 \\
\hline 11 & 1.0256 & 4.9449 & 28 & 1.0232 & 5.8392 \\
\hline 12 & 1.0201 & 5.1552 & 29 & 1.0199 & 5.9478 \\
\hline 13 & 1.0181 & 5.2608 & 30 & 1.0162 & 6.1066 \\
\hline 14 & 1.0168 & 5.3137 & 31 & 1.0154 & 6.1449 \\
\hline 15 & 1.0156 & 5.3593 & 32 & 1.0151 & 6.1586 \\
\hline 16 & 1.0138 & 5.4563 & & & \\
\hline & & & & & \\
\hline
\end{tabular}

Table 8. comparison results

\begin{tabular}{|c|c|c|}
\hline & $\begin{array}{c}\text { Before } \\
\text { installation }\end{array}$ & $\begin{array}{c}\text { After } \\
\text { installation }\end{array}$ \\
\hline $\mathrm{P}_{\text {loss }}(\mathrm{kw})$ & 587 & 324 \\
\hline $\mathrm{THD}_{\max }(\%)$ & 13.44 & 6.15 \\
\hline $\mathrm{V}_{\max }(\mathrm{pu})$ & 1 & 1.03 \\
\hline $\mathrm{V}_{\min }(\mathrm{pu})$ & 0.87 & 0.99 \\
\hline
\end{tabular}

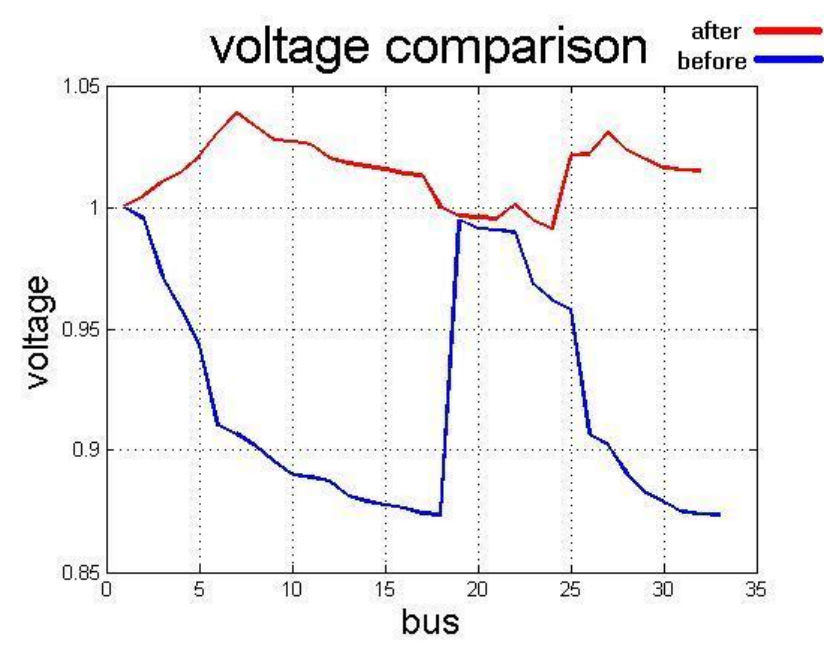

Fig. 5. voltage comparison

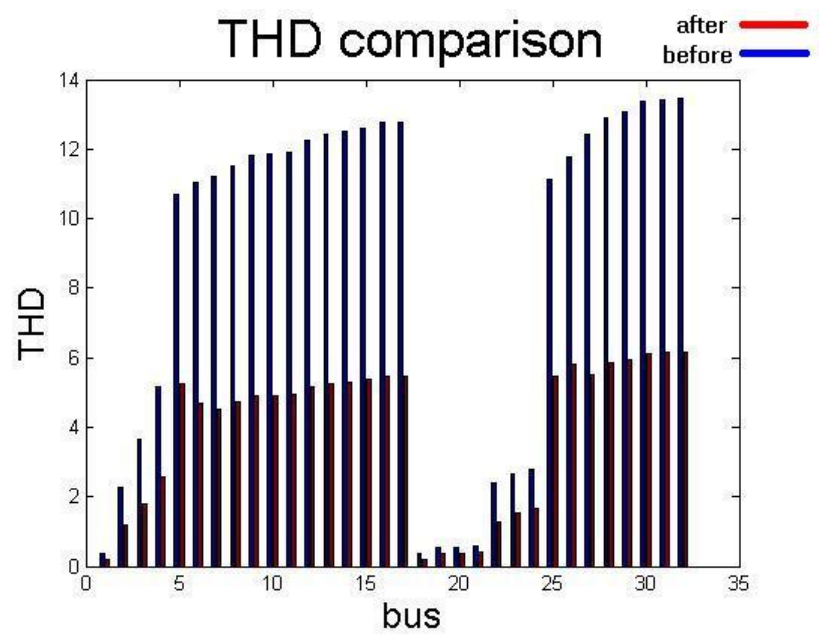

Fig. 6. THD comparison

\subsection{Scenario 2:}

This scenario is like the first scenario but in this scenario distributed generations are armed with harmonic injection system. The rms voltages and THD of all buses for the base case are the same as the first scenario (table5) In table 9 the locations and sizes of capacitors and Distributed generations after running of the algorithm are given. In table 10, rms voltages and THD of all buses after installation of capacitor and DG are demonstrated. 
TABLE 9. the locations of capacitors and DGs with proposed method

\begin{tabular}{|c|c|c|c|c|c|}
\hline Bus & $\begin{array}{c}\text { Capacitor } \\
\text { (KVAR) }\end{array}$ & $\begin{array}{c}\text { DG } \\
(\mathrm{KW})\end{array}$ & Bus & $\begin{array}{c}\text { Capacitor } \\
\text { (KVAR) }\end{array}$ & $\begin{array}{c}\mathrm{DG} \\
(\mathrm{KW})\end{array}$ \\
\hline 0 & - & - & 17 & - & - \\
\hline 1 & - & - & 18 & - & - \\
\hline 2 & - & - & 19 & - & - \\
\hline 3 & 1200 & - & 20 & - & - \\
\hline 4 & - & - & 21 & - & - \\
\hline 5 & - & 3000 & 22 & - & - \\
\hline 6 & 1200 & - & 23 & 300 & - \\
\hline 7 & - & - & 24 & - & - \\
\hline 8 & - & - & 25 & - & - \\
\hline 9 & - & - & 26 & - & 800 \\
\hline 10 & - & - & 27 & - & - \\
\hline 11 & - & - & 28 & - & - \\
\hline 12 & - & - & 29 & - & - \\
\hline 13 & - & - & 30 & - & - \\
\hline 14 & 2700 & - & 31 & 1200 & - \\
\hline 15 & - & - & 32 & - & - \\
\hline 16 & - & - & & & \\
\hline
\end{tabular}

Table 10. bus voltage and THD after installation of capacitor and DG

\begin{tabular}{|c|c|c|c|c|c|}
\hline $\begin{array}{c}\text { Bus } \\
\text { number }\end{array}$ & $\mathrm{V}_{\text {rms }}$ & THD $_{\mathrm{v}}$ & $\begin{array}{c}\text { Bus } \\
\text { number }\end{array}$ & $\mathrm{V}_{\mathrm{rms}}$ & $\begin{array}{c}\mathrm{THD}_{\mathrm{v}} \\
\mathrm{THD}_{\mathrm{v}}\end{array}$ \\
\hline 0 & 1 & - & 17 & 0.994749 & 2.264492 \\
\hline 1 & 1.000106 & 0.06176 & 18 & 0.999579 & 0.080894 \\
\hline 2 & 1.002447 & 0.356496 & 19 & 0.996013 & 0.218172 \\
\hline 3 & 1.006762 & 0.514209 & 20 & 0.995311 & 0.251373 \\
\hline 4 & 1.010194 & 0.643469 & 21 & 0.994675 & 0.283997 \\
\hline 5 & 1.018787 & 1.105631 & 22 & 0.999515 & 0.453077 \\
\hline 6 & 1.020674 & 1.355118 & 23 & 0.994321 & 0.663298 \\
\hline 7 & 1.016424 & 1.417705 & 24 & 0.991068 & 0.769031 \\
\hline 8 & 1.011336 & 1.58226 & 25 & 1.022891 & 1.125548 \\
\hline 9 & 1.00667 & 1.737671 & 26 & 1.028765 & 1.151569 \\
\hline 10 & 1.005939 & 1.750403 & 27 & 1.020071 & 1.407597 \\
\hline 11 & 1.004675 & 1.773063 & 28 & 1.013881 & 1.603993 \\
\hline 12 & 1.000132 & 1.95855 & 29 & 1.01112 & 1.666835 \\
\hline 13 & 0.998716 & 2.058011 & 30 & 1.009118 & 1.804092 \\
\hline 14 & 0.997911 & 2.110823 & 31 & 1.008957 & 1.835133 \\
\hline 15 & 0.997167 & 2.154567 & 32 & 1.0087 & 1.847445 \\
\hline 16 & 0.995306 & 2.246032 & & & \\
\hline
\end{tabular}

As observed before, in the first scenario, installation of these devices couldn't reduce THD below the maximum allowable of THD, defined by standard IEEE-519. But in this scenario THD of all buses are less than \%5. The controlling systems of distributed generations by harmonic injection not only increase the amplitude of fundamental harmonic of buses but also decrease the amplitude of other harmonics of buses. This result THD of the system decrease below the $5 \%$ before the voltage of the systemexceeds the $1.05 \%$.

In table 11 and Fig. 7 and Fig. 8 the results of two cases (before installation and after installation) are compared.

Table 11. comparison results

\begin{tabular}{|c|c|c|}
\hline & $\begin{array}{c}\text { Before } \\
\text { installation }\end{array}$ & $\begin{array}{c}\text { after } \\
\text { installation }\end{array}$ \\
\hline $\mathrm{P}_{\text {loss }}(\mathrm{kw})$ & 587 & 301 \\
\hline $\mathrm{THD}_{\max }(\%)$ & 13.44 & 2.26 \\
\hline $\mathrm{V}_{\max }(\mathrm{pu})$ & 1 & 1.02 \\
\hline $\mathrm{V}_{\min }(\mathrm{pu})$ & 0.87 & 0.99 \\
\hline
\end{tabular}

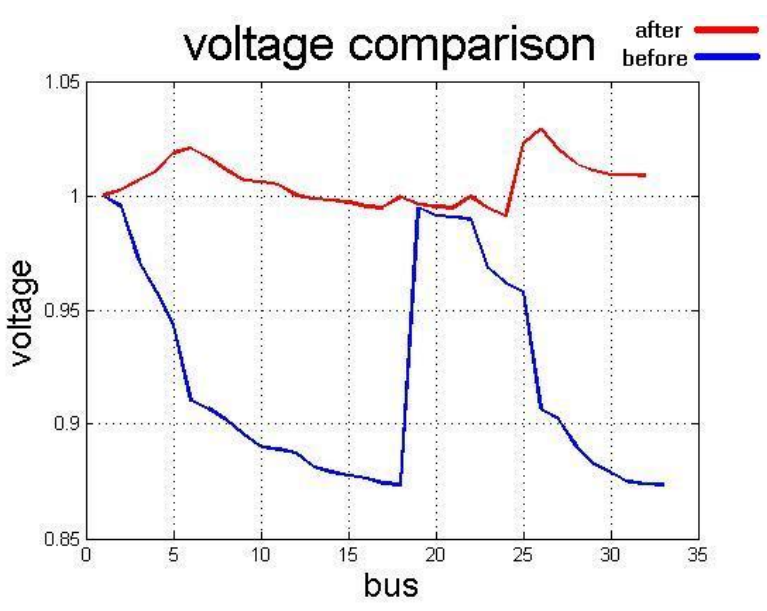

Fig. 7. voltage comparison

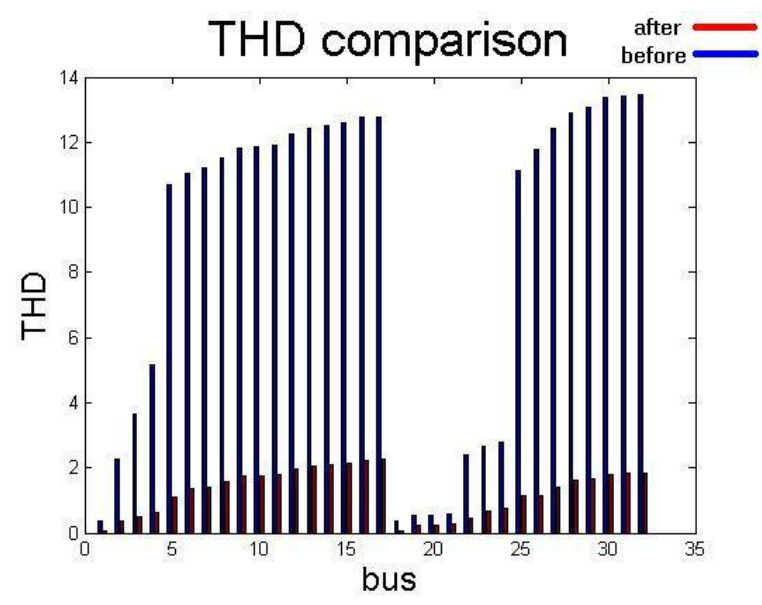

Fig. 8. THD comparison

\section{CONCLUSION}

In this paper a modified version of PSO algorithm (DPSO) which is suitable for discrete problems is applied for optimal placing and sizing of capacitor and PowerElectronic Interfaced Distributed Generation in distribution system. In this paper harmonic injection controlling system is used for DGs for improving system's power quality. For evaluating this controlling 
system and objective function, the IEEE 33-bus test system is modified and employed. This paper contains two scenarios. Simulations show that in a light harmonic pollution, installation of capacitors and DGs can reduce total harmonic distortion (THD) in the system to an acceptable range by increasing the amplitude of fundamental harmonic. But in a heavy pollution they can't reduce harmonic to acceptable range before exceeding the bus voltages over upper bounds of acceptable range defined by standards. In this situation use of such converter for reducing harmonic is so effective. Simulations show the usefulness of these electronic interfaces.

\section{REFERENCES}

[1] K. Nara, Y. Hayashi, K. Ikeda, T. Ashizawa," Application of tabu search to optimal placement of distributed generators", IEEE PES Winter Meeting, vol. 2, 2001, pp. 918-923.

[2] H.L. Willis," Analytical methods and rules of thumb for modeling DG distribution interaction",IEEE PES Summer Meeting, vol. 3, Seattle,WA, Jul 2000.

[3] N. Acharya, P. Mahat, N. Mithulananthan, "An analytical approach for DG allocation in primary distribution network, Int. J. Electr. Power Energy Syst. 2006, PP.669-678.

[4] K.H. Kim, Y.J. Lee, S.B. Rhee, S.K. Lee, S.-K. You, "Dispersed generator placement using fuzzy-GA in distribution sy stems", in: IEEE PES Summer Meeting, vol. 3 July, 2002, pp. 1148-1153.

[5] Y.A. Katsigiannis, P.S. Georgilakis," Optimal sizing of small isolated hybrid power systems using tabu search", Journal of Optoelectronics and Advanced Materials 10 (5) (2008) 1241-1245.

[6] J.O. Kim, S.W. Nam, S.K. Park, C. Singh, "Dispersed generation planning using improved Hereford Ranch algorithm", Electr. Power Syst. 1998.

[7] J. Kennedy, R. Eberhart, "Particle swarm optimization", IEEE . Conf. Neural Networks, Perth, Australia, November 1995, pp. 1942-1948.

[8] K.E. Parsopoulos, M.N. Vrahatis," On the computation of all minimizers through particle swarm optimization, IEEE Trans. Evolut. Comput,2004,PP.211-224.

[9] X. Yu, X. Xiong, Y. Wu," A PSO-based approach to optimal capacitor placement with harmonic distortion consideration", Electr. Power Sy st. 2004,227-233.

[10] R.A. Krohling, L.S. Coelho," Co-evolutionary particle swarm optimization using Gaussian distribution for solving constrained optimization problems" IEEE Trans. Sy st,2006,PP. 1407-1416.

[11] U. Baumgartner, C. Magele, W. Renhart, "Pareto optimality and particle swarm optimization", IEEE Trans. 2004,PP.1172-1175.

[12] "Modeling and Simulation of the Propagation of Harmonics in Electric Power Network Part I: Concepts, Models and Simulation Techniques," Task Force on Harmonics Modeling and Simulation, IEEE Trans. on PWRD, Vol. 11, No. 1, Jan. 1996 pp. 452-465.

[13] H.Patel,W.Agarwal," Control of a Stand-Alone InverterBased Distributed Generation Source for Voltage Regulation and Harmonic Compensation",IEEE,trans.on power delivery, 2008,pp 1113-1120

[14] L.F. Ochoa, A. Padilha-Feltrin, G.P. Harrison, "Evaluating distributed generation impacts with a multiobjective index", IEEE Transactions on Power Delivery 2006,pp.1452-1458.
[15] J. Kennedy and R. C. Eberhart, "A Discrete Binary Version of the Particle Swarm Algorithm Proc. of the conference on Systems, Man, 1997, pp.4104-4109.

[16] S.K. Goswami, S.K. Basu, A new algorithm for the reconfiguration of distribution feeders for loss minimization, IEEE Trans,1992,1484-1491.

[17] Abou-Ghazala,A.,"optimal capacitor placement in Distribution Systems Feeding non linear loads",IEEE Bolgona Power Teach conference,2003.

\section{Authors' Profiles}

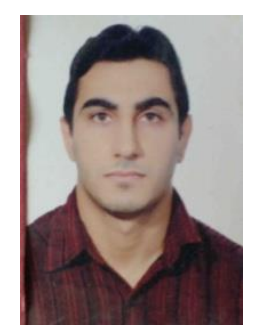

Mohamadreze Heydari sharafdarkolai was born in sari,mazandaran,Iran in 1985.recieved B.S and M.S degree from babol university of technology in 2010 and 2013. Now he is a staff member of Mazandaran regional electric company, Iran

Hamed Dehghan Niyazi was born in babol in 1982. recieved B.S degree in ali abad katol university, is a graduate student of Azad university of y azd, Iran

T. Daemi was born in Iran, in 1979. She received the B.Sc degree from Yazd University, Yazd, Iran, in 2002, M.Sc degree from Shiraz University, Shiraz, Iran in 2005, and Ph.D degree from Isfahan University of Technology, Isfahan, Iran in 2012. Currently, she is assistant professor at Islamic Azad University of Yazd, Yazd, Iran. Her research interest is reliability and security analysis of power systems, with application of data mining and Bayesian Networks in power systems.

Ali Akbar Kasiri is a staff member of babol Tozi Company

How to cite this paper: Mohamadreza Hey dari Sharafdarkolai, Hamed Dehghan Niyazi, Tahere daemi, Ali Akbar Kasiri,"Optimal Placement and Sizing of Capacitor and PowerElectronic Interfaced Distributed Generation in Heavy Harmonic Polluted Sy stems", International Journal of Intelligent Systems and Applications(IJISA), vol.6, no.7, pp.52-59, 2014. DOI: 10.5815/ijisa.2014.07.07 